\title{
Dexmedetomidine reduces inflammation in mice with acute pancreatitis by inhibiting NLRP3 inflammasome and sympathetic nerve activity
}

\author{
Yanjun Gao1, JinHui Xie ${ }^{2}$, Ruobin Liư ${ }^{1}$, Yue Li ${ }^{3}$, Wenjun Yan ${ }^{1 *}$ \\ ${ }^{1}$ Department of Anesthesiology, Gansu People's Hospital, ${ }^{2}$ Department of Ultrasound, Gansu People's Hospital, Lanzhou, \\ ${ }^{3}$ Department of Digestion, The First Hospital Affiliated to ShanXi Medical University, Taiyuan, PR China
}

*For correspondence: Email: qzyk59@163.com

Sent for review: 18 December 2019

Revised accepted: 26 April 2020

\begin{abstract}
Purpose: To study the anti-inflammatory influence of dexmedetomidine (DEX) in mice with acute pancreatitis $(A P)$, and to determine the underlying mechanism.

Methods: A total of 75 healthy ICR male mice were randomly divided into control, mild acute pancreatitis (MAP), MAP+DEX, severe acute pancreatitis (SAP), and SAP+DEX groups, with 15 mice/group. Blood levels of inflammatory factors (TNF- $\alpha$ and IL-1 $\beta$ ) and norepinephrine were assayed in each group. Western blotting was used to assay the protein expressions of NLRP3 and norepinephrine transporter (NET) in the pancreatic tissue of each group.

Results: The levels of inflammatory factors in the MAP+DEX group were markedly lower than those in the MAP group after $10 \mathrm{~h}$ of MAP induction $(p<0.01)$. Mice in MAP+DEX group had significantly lower expression of NLRP3 in pancreatic tissue, and significantly higher NET protein level, relative to the MAP mice. Following $10 \mathrm{~h}$ of SAP, concentrations of the inflammatory factors and the pancreatic expression of NLRP3 were lower in SAP+DEX-treated mice than in SAP mice, while NET protein was significantly higher in SAP mice $(p<0.01)$.

Conclusion: DEX reduces the expressions of inflammation-related factors TNF- $\alpha$ and $I L-1 \beta$, and inhibits inflammatory response in mice with $A P$ via downregulation of NET protein expression via inhibition of NLRP3 and early sympathetic events.
\end{abstract}

Keywords: Dexmedetomidine, NLRP3 inflammasome, Sympathetic nerve, Acute pancreatitis, Inflammatory response

\begin{abstract}
This is an Open Access article that uses a fund-ing model which does not charge readers or their institutions for access and distributed under the terms of the Creative Commons Attribution License (http://creativecommons.org/licenses/by/4.0) and the Budapest Open Access Initiative (http://www.budapestopenaccessinitiative.org/read), which permit unrestricted use, distribution, and reproduction in any medium, provided the original work is properly credited.

Tropical Journal of Pharmaceutical Research is indexed by Science Citation Index (SciSearch), Scopus, International Pharmaceutical Abstract, Chemical Abstracts, Embase, Index Copernicus, EBSCO, African Index Medicus, JournalSeek, Journal Citation Reports/Science Edition, Directory of Open Access Journals (DOAJ), African Journal Online, Bioline International, Open-J-Gate and Pharmacy Abstracts
\end{abstract}

\section{INTRODUCTION}

Acute pancreatitis (AP) is a hemorrhage, edema, or necrotizing inflammatory response caused by pancreatic enzyme digestion of pancreatic tissue due to a variety of reasons. The disease varies in severity, with MAP having a good prognosis.
However, a small number of SAP patients often have serious secondary infections, leading to persistent systemic inflammatory response syndrome (SIRS) and multiple organ dysfunction syndrome (MODS), with extremely high mortality which may be up to $6.0 \%$ after active treatment [1]. The early inflammatory reaction period is 
often accompanied by multiple organ dysfunction and organ failure, and it is the stage at which AP patients are prone to death.

Studies have shown that continuous stimulation of sympathetic nerves is closely associated with excessive activation of inflammation. Studies have found that sympathetic abnormal excitability is associated with poor prognosis in patients with ACS [2]. Therefore, it is important to actively reduce excessive sympathetic nerve excitability in AP patients so as to decrease pancreatic inflammation and pancreatic injury.

Dexmedetomidine (DEX), a classical selective a2 receptor agonist, significantly reduces sympathetic nerve activity. Thus, it has been widely used in sedation and analgesia in critically-ill patients. Studies have shown that DEX maintains hemodynamic stability in some patients with underlying cardiovascular disease during perioperative period. It is well-established that DEX exerts good protective effect on multiple organ organs in the body $[3,4]$. In addition, research has found that DEX reduces the serum levels of inflammatory factors such as TNF- $\alpha$ and $\mathrm{IL}-1 \beta$, resulting in decreases in the degree of inflammatory response before or during surgery.

Some animal experiments have also demonstrated that DEX significantly reduced myocardial ischemia-reperfusion injury in experimental animals, and also reduced the levels of inflammatory factors [5]. However, not much is known about the relationship between DEX and AP.

The present study was carried out to unravel the influence of DEX on the level of inflammatory response in mice with $\mathrm{AP}$, and the underlying mechanisms. This was with a view to providing more clinical evidence for early prevention and treatment of patients with AP.

\section{EXPERIMENTAL}

\section{Animals and grouping}

A total of 75 healthy ICR male mice weighing 200 - $250 \mathrm{~g}$ were used in this study. They were subjected to adaptive feeding for 1 week and provided clean drinking water in an environment with a temperature of $25{ }^{\circ} \mathrm{C}$. The mice were thereafter randomly divided into control, MAP, SAP, MAP + DEX, and SAP + DEX groups, with 15 mice in each group. Mice in the MAP group were intraperitoneally injected 10 times with $\mathrm{CAE}$ at a dose of $50 \mu \mathrm{g} / \mathrm{kg} / \mathrm{h}$. Mice in the SAP group were intraperitoneally injected 10 times with $\mathrm{CAE}$
(50 $\mu \mathrm{g} / \mathrm{kg} / \mathrm{h}$ ), with lipopolysaccharide (LPS, 10 $\mathrm{mg} / \mathrm{kg}$ ) added at the last injection.

Mice in the MAP + DEX mice were injected with DEX $(20 \mu \mathrm{g} / \mathrm{kg})$ via the tail vein, in addition to the treatment in the MAP group, while the same DEX dose was given through tail injection to SAP + DEX mice, in addition to the treatment in the SAP group. In contrast, mice in the control group were intraperitoneally injected with normal saline. This research was approved by the Animal Ethical Committee of Gansu People's Hospital (approval no. 20190121), and conducted according to "Principles of Laboratory Animal Care" (NIH publication no. 85-23, revised 1985) [6].

\section{Reagents}

The reagents used were $1 \%$ pentobarbital solution, dexmedetomidine $(200 \mathrm{mg} / \mathrm{mL}), 0.9 \%$ sodium chloride solution, $5 \%$ BSA solution, caerulein solution, and citrate antigen repair solution.

\section{Treatments}

After 12 hours, the AP mice were routinely anesthetized with $1 \%$ pentobarbital solution, and blood samples were taken from their tail veins. The blood samples were centrifuged at $4000 \mathrm{rpm}$ for $10 \mathrm{~min}$ at $4{ }^{\circ} \mathrm{C}$, and the supernatants (sera) were collected in EP tubes.

Serum levels of inflammatory factors TNF- $\alpha$ and IL-1 $\beta$, and serum norepinephrine (NE) levels were measured using ELISA, in line with the specific assay procedures outlined in the ELISA kits. After blood collection, the mice were sacrificed via cervical dislocation, and the hearts were exposed to systemic perfusion. At the end of the experiment, pancreatic tissue was taken from each group for assay of the protein expressions of NLRP3 and NET using Western blotting.

\section{Statistical analysis}

Results are presented as mean \pm SD. Statistical analysis was done with one-way ANOVA. Paired data or independent samples were compared with $t$-test. Differences between non-normal distribution data were analyzed using rank sum test. Statistical analysis was done with SPSS 20.0 software. Gel image processing software was used to analyze the results of Western blotting. Count data are expressed as percentage, and the comparison between the groups was done with $x^{2}$ test. Statistical significance was assumed at $p<0.05$. 


\section{RESULTS}

Effect of DEX on concentrations of inflammatory factors TNF- $\alpha$ and IL-1 $\beta$ in AP mice

The results of ELISA showed that after $10 \mathrm{~h}$ of $A P$, the levels of serum inflammatory factors TNF- $\alpha$ and IL- $1 \beta$ in MAP, SAP, MAP + DEX, and $\mathrm{SAP}+\mathrm{DEX}$ groups were significantly higher than the corresponding levels in the control group $(p<$ 0.01 ). The serum concentrations of TNF- $\alpha$ and $\mathrm{IL}-1 \beta$ in mice in the MAP+DEX group were significantly lower than those of mice in the MAP group after $10 \mathrm{~h}$ of MAP $(p<0.01)$. These results are shown in Figure 1. As shown in Figure 2, after $10 \mathrm{~h}$ of SAP, the levels of TNF- $\alpha$ and IL-1 $\beta$ in the SAP + DEX group were significantly lower than those in SAP group $(p<0.01)$.

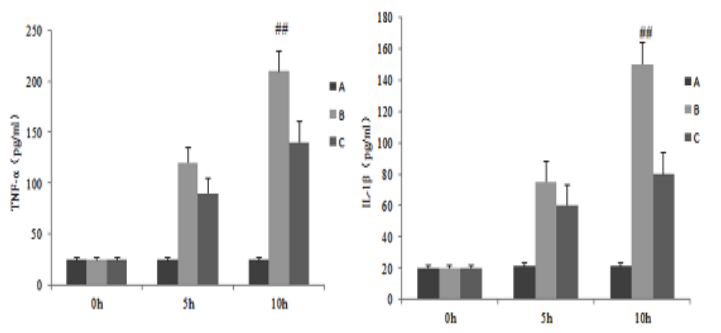

Figure 1: Effect of DEX on serum levels of TNF- $\alpha$ and IL-1 $\beta$ in mice with MAP. A: Control group; B: MAP

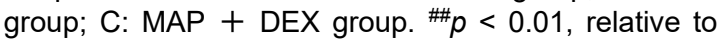
MAP + DEX group
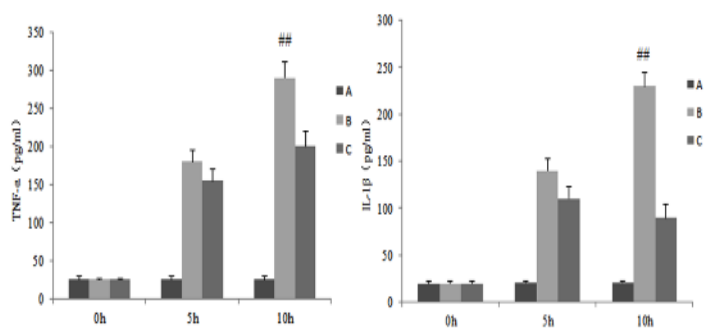

Figure 2: Effect of DEX on serum levels of TNF- $\alpha$ and IL-1 $\beta$ in mice with SAP. A: Control group; B: SAP group; C: SAP + DEX group. ${ }^{\#} p<0.01$, compared with SAP + DEX

\section{Effect of DEX on pancreatic protein expressions of NLRP3 and NET}

The results of Western blotting showed that the expression of NLRP3 in pancreatic tissues was markedly reduced in MAP + DEX-treated mice, when compared with mice given MAP, while NET protein concentration was markedly lower in MAP-treated mice $(p<0.05)$. The pancreatic tissue expression of NLRP3 was markedly lower in SAP+DEX mice than in SAP-treated mice, while NET protein concentration was markedly lower in SAP-treated mice $(p<0.01)$. These results are presented in Figure 3.

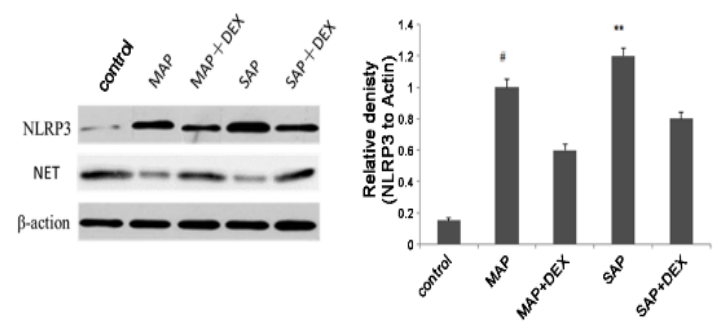

Figure 3: Effect of DEX on pancreatic expressions of NLRP3 and NET proteins in mice with mild and severe acute pancreatitis; ${ }^{\#} p<0.05$, compared with MAP + DEX group; ${ }^{* *} p<0.01$, compared with SAP + DEX group

\section{Effect of DEX on serum NE expression in mice with AP}

As shown in Figure 4, the expression of NE in serum of mice given MAP + DEX was lower than that in MAP-treated mice after $10 \mathrm{~h}$ of AP $(p<$ $0.01)$. The expression of $N E$ in serum of mice given SAP + DEX was markedly lower than that in SAP-treated mice $(p<0.01)$.

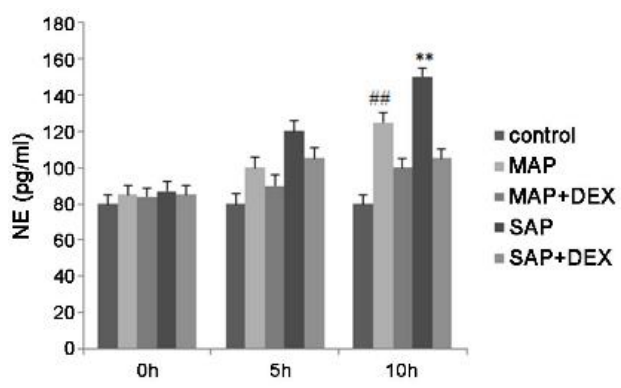

Figure 4: Influence of DEX on serum NE expression in mice with AP; \#\#p < 0.01, vs MAP + DEX group; ${ }^{*} p$ $<0.01$, vs SAP + DEX group

\section{DISCUSSION}

Acute pancreatitis (AP) is an inflammatory reaction due to various causes, in which pancreatic tissue is digested, and becomes hemorrhagic, edematous, or even necrotic. In recent years, the incidence of AP has increased in China. The disease, especially SAP, is often accompanied with excessive activation of inflammatory reactions secondary to MODS, and high mortality in the early stage. After 60 days of active treatment, AP-associated mortality still exceeds $6.0 \%$ [7]. Therefore, control of inflammatory response is a key part of the treatment strategy for AP. 
Related animal studies have found that CAE has an excitatory effect on the vagus nerve, thereby enhancing the secretory function of the pancreatic acinus at physiological levels. In contrast, when plasma cholecystokinin (CCK) is at a super-physiological level, it can directly excite neurons in the pancreas and act on the acinus, leading to AP. Specific removal of primary sensory neurons in the pancreas results in significant amelioration of AP in rats [8]. This indicates that AP-induced inflammation is regulated by the corresponding autonomic nervous system. Inflammatory reflex is a physiological pathway in which the autonomic nervous system senses inflammatory stimuli and promotes the secretion of inflammation-related cytokines. The signal transduction pathway located in the vagus nerve is equivalent to its afferent and efferent pathways, which exert negative feedback regulation on the inflammatory response. In a sense, the excitability of the vagal pathway inhibits the degree of inflammatory response in pancreatic tissue. If the vagus nerve and sympathetic nerve function are balanced by an external force, it may have positive effects on the control of AP-associated inflammatory response $[9,10]$.

Dexmedetomidine (DEX), a classical selective a2 receptor agonist, has a wide range of physiological effects such as anti-inflammatory, anti-apoptotic and anti-oxidative properties, and it exerts a significant lowering effect on sympathetic nerve activity [11]. Clinically, DEX is effective in reducing the sympathetic hyperactivity caused by cocaine addiction. In addition, the administration of DEX in critically-ill patients also reduces the release of inflammatory factors. Sympathetic excitability increases in the early stage of AP, especially in the early stage of SAP, and it is often accompanied by severe inflammatory reactions.

Sympathetic inhibition of DEX may have a certain significance in reducing inflammation. This study found that DEX alleviated the degree of inflammation in mice with mild and severe pancreatitis, as reflected in decreases in serumrelated inflammatory factors such as TNF- $\alpha$ and $I L-1 \beta$. This may be due to activation of presynaptic a2 receptor and inhibition of the secretion of sympathetic norepinephrine. In addition, being a selective a2 adrenergic receptor agonist, DEX relies on agonistic a2 adrenergic receptors to stimulate proinflammatory cells such as leukocytes and macrophages, while inhibiting the expression of Toll-like receptor 4, thereby suppressing nuclear transcription and NF-KB inflammatory response pathway $[12,13]$.
In addition, this study has demonstrated that, in mice with mild or severe pancreatitis, DEX markedly reduced level of NLRP3 inflammasome which is considered a crucial marker of $A P$ severity. The inhibition of DEX may be explained viz: AP in mice produces stimulation of sympathetic nerves, significant increases in norepinephrine, and extremely severe inflammatory response. These risk signals stimulate the expression of NLRP3 inflammasome [14]. By inhibiting sympathetic nerve activity, DEX reduces the production of nociceptive cytokines, thereby inhibiting the inflammatory pathway of NLRP3 and exerting anti-inflammatory effect [15].

Sympathetic excitation releases a large amount of norepinephrine, more than $80 \%$ of which is taken up by nerve endings via norepinephrine transporter (NET). This protein transporter is involved in regulating the concentration and duration of norepinephrine released by sympathetic nerves into the prominent gap [16]. This study found that the NET protein level in the DEX group was markedly elevated, relative to that in the pancreatitis group, indicating that DEX regulated norepinephrine levels in the presynaptic membrane, and also decreased its level in the protrusion space by increasing NET expression, thereby reducing sympathetic nerve activity. This achieved the purpose of reducing inflammatory response in AP mice.

\section{CONCLUSION}

Dexmedetomidine (DEX) reduces the expression levels of the inflammation-related factors, TNF- $\alpha$ and IL-1 $\beta$, and inhibits inflammatory response in mice with AP. The mechanism involved in this process may be related to the downregulation of NET protein by inhibition of NLRP3 and suppression of early sympathetic nerve activity. These findings indicate that clinically, DEX may be useful as a therapeutic target for alleviating AP-associated inflammatory response through blockage of early sympathetic nerve activity in AP patients.

\section{DECLARATIONS}

\section{Conflict of interest}

No conflict of interest is associated with this work.

\section{Contribution of authors}

This study was done by the authors named in this article, and the authors accept all liabilities 
resulting from claims which relate to this article and its contents. The study was conceived and designed by Wenjun Yan, Yanjun Gao, JinHui Xie, Ruobin Liu, Yue Li. Wenjun Yan collected and analyzed the data, while Yanjun Gao and JinHui Xie wrote the manuscript. All authors read and approved the manuscript for publication. Yanjun Gao and JinHui Xie contributed equally to this work and should be considered as co-first authors.

\section{Open Access}

This is an Open Access article that uses a funding model which does not charge readers or their institutions for access and distributed under the terms of the Creative Commons Attribution License (http://creativecommons.org/licenses/by/ 4.0) and the Budapest Open Access Initiative (http://www.budapestopenaccessinitiative.org/rea d), which permit unrestricted use, distribution, and reproduction in any medium, provided the original work is properly credited.

\section{REFERENCES}

1. Wang CY, Yang M. Guidelines for the Diagnosis and Treatment of Acute Pancreatitis (2014) -- Analysis of Difficulties in Surgical Diagnosis and Treatment of Acute Pancreatitis. J Clin Surg 2015; 1(1): 11-13.

2. Yang YC, Huang GW, Li YX, Sun WJ. Prognostic analysis of percutaneous catheter drainage for acute pancreatitis complicated with necrotizing infection. J Hepatobiliary Pancreat Surg 2015; 27(2): 94-96.

3. Guo JC, Liu Y. Study on CT Score of Extrapubic Inflammation in Acute Pancreatitis and Its Correlation with CT Ratio of Liver to Spleen. J Clin Pract Hospital 2015; 1(1): 61-63.

4. Sayos J, Wu C, Morra M, Wang $N$, Zhang X, Allen D, van Schaik S, Notarangelo L, Geha R, Roncarolo MG, et al. Pillars Article: The X-Linked Lymphoproliferative Disease Gene Product SAP Regulates Signals Induced through the Co-Receptor SLAM. Nature 1998. 395: 462469. J Immunol 2017; 199(5): 1534.

5. Calpe S, Wang N, Romero X, Berger SB, Lanyi A, Engel $P$, Terhorst $C$. The SLAM and SAP gene families control innate and adaptive immune responses. Adv Immunol 2015; 97: 177-250.
6. World Health Organization. Principles of laboratory animal care. WHO Chron 1985; 39: 51-56.

7. Bernhardt J, Churilov L, Dewey H, Lindley RI, Moodie M, Collier J, Langhorne P, Thrift AG, Donnan G. AVERT Collaborators. Statistical analysis plan (SAP) for A Very Early Rehabilitation Trial (AVERT): an international trial to determine the efficacy and safety of commencing out of bed standing and walking training (very early mobilization) within $24 \mathrm{~h}$ of stroke onset vs. us. Int J Stroke 2015; 10: 23-24.

8. Rothe R, Timofte R, Gool LV. DEX: Deep Expectation of Apparent Age from a Single Image. IEEE International Conference on Computer Vision Workshop 2015.

9. Mahler J, Liang J, Niyaz S, Laskey M, Doan R, Liu XY, Aparicio J, Goldberg K. Dex-Net 2.0: Deep Learning to Plan Robust Grasps with Synthetic Point Clouds and Analytic Grasp Metrics. Conference Paper 2017; 3(1): 14.

10. Li B, Zhang Y, Li J, Yang WB, Gu DW. AppSpear: Automating the Hidden-Code Extraction and Reassembling of Packed Android Malware. J Systems and Software 2018; 140: 3-16.

11. He $Y$, Hara $H$, Núñez $G$. Mechanism and regulation of NLRP3 inflammasome activation. Trends Biochem Sci 2016; 41(12): 1012.

12. Elliott El, Sutterwala FS. Initiation and perpetuation of NLRP3 inflammasome activation and assembly. Immunol Rev 2015; 265(1): 35-52.

13. Abderrazak A, Syrovets $T$, Couchie D, El Hadri K, Friguet $B$, Simmet T, Rouis M. NLRP3 inflammasome: From a danger signal sensor to a regulatory node of oxidative stress and inflammatory diseases. Redox Biol 2015; 4(3): 296-307.

14. Zaga-Clavellina V, Martha RV, Flores-Espinosa $P$. In vitro secretion profile of pro-inflammatory cytokines $I L-1 \beta$, $T N F-\alpha, \quad I L-6$, and of human beta-defensins (HBD)-1, $H B D-2$, and $H B D-3$ from human chorioamniotic membranes after selective stimulation with Gardnerella vaginalis. Am J Reprod Immunol 2015; 67(1): 34-43.

15. Park JY, Chung TW, Jeong YJ, Kwak CH, Ha SH, Kwon $K M$, Abekura $F$, Cho $S H$, Lee YC, Ha KT, et al. Ascofuranone inhibits lipopolysaccharide-induced inflammatory response via NF-kappaB and $A P-1, p$ ERK, TNF- $\alpha, \quad I L-6$ and $I L-1 \beta$ in RAW 264.7 macrophages. Plos One 2017; 12(2): 171322.

16. An L, Li J, Jin ZL, Li YF, Li J, Zhang YZ. Construction and functional identification of stable expression cell lines of human norepinephrine transporter. Chin J Pharmacol Toxicol 2015; 29(1): 92-97. 